\title{
Social and reproductive physiology and behavior of the Neotropical cichlid fish Cichlasoma dimerus under laboratory conditions
}

\author{
Felipe Alonso $^{1}$, Maximiliano Cánepa ${ }^{1}$, Renata Guimarães Moreira ${ }^{2}$ and Matías Pandolfi ${ }^{1}$
}

In this work we describe for the first time the social and reproductive behavior of the Neotropical fish Cichlasoma dimerus (Heckel, 1840) [Perciformes: Cichlidae], endemic to the Paraná River basin, using a comprehensive-integral approach, including morphological and physiological features. This substrate breeding fish has biparental care of the fry and presents a dominance hierarchy that determines access to breeding territories among males, and to males with territories among females. Gregarious behavior associated with a pale body color, was observed before reproductive behaviors started. Afterwards, a dominance hierarchy was established through aggressive interactions. Territorial individuals had bright body color patterns and non territorial an opaque grey one. Black ventral coloration was associated with reproductive individuals. Courtship displays, which were similar to threatening displays, had the common effect of increasing the visible area of the individual. The dominant male was always the largest one suggesting that size is probably a major factor determining the hierarchy establishment and that these intra-sexually selected traits may have been reinforced by inter-sexual selection. Reproductive males had higher pituitary levels of $\beta$-follicle stimulating hormone ( $\beta$-FSH) and somatolactin (SL) than non reproductive ones, while no differences were found among females. No differences were found among male gonadosomatic indexes. Non reproductive individuals had higher plasma cortisol levels for both sexes. It is possible that dominant reproductive individuals may be inhibiting reproduction of subordinate fish through physical contact, increasing their cortisol levels and diminishing FSH and SL pituitary content. However, this was not reflected as an inhibition at the gonadal level in our experimental design.

En este trabajo se describen por primera vez el comportamiento social y reproductivo del pez cíclido neotropical Cichlasoma dimerus (Heckel, 1840) [Perciformes: Cichlidae], endémico de la cuenca del Paraná, desde un enfoque integral y abarcador, incluyendo características morfológicas y fisiológicas. Éste pez incubador de substrato, tiene cuidado biparental de las crías y presenta una jerarquía de dominancia que determina el acceso a territorios reproductivos entre los machos, y a machos con territorios entre las hembras. Se observó un comportamiento gregario con una coloración corporal pálida característica, antes que comenzaran los comportamientos reproductivos. Luego, una jerarquía de dominancia se estableció a través de interacciones agresivas. Los individuos territoriales presentaron patrones de coloración corporal brillantes y los individuos no territoriales uno gris opaco. Una coloración ventral oscura fue observada asociada a individuos reproductivos. Los despliegues de cortejo fueron similares a los de amenaza y tuvieron la característica común de aumentar el área visible de los peces. El macho dominante fue siempre el más grande, sugiriendo que probablemente la fuerza (tamaño) es un factor preponderante determinando el establecimiento de las jerarquías y que éstas características seleccionadas intrasexualmente pueden haber sido reforzadas por selección intersexual. Los machos reproductivos presentaron un mayor contenido hipofisario de $\beta$-FSH y SL que aquellos no reproductivos, mientras que no se encontraron diferencias entre las hembras. No se encontraron diferencias entre los índices gonadosomáticos de los machos. Los individuos no reproductivos presentaron niveles plasmáticos mayores de cortisol para ambos sexos. Aunque los individuos reproductivos dominantes podrían estar inhibiendo la reproducción de los peces menos dominantes a través de interacciones de contacto físico, aumentando sus niveles de cortisol y disminuyendo el contenido hipofisario de FSH y SL, esto no se vería reflejado a nivel gonadal en nuestro diseño experimental.

Key words: Cichlidae, Cortisol, Gonadosomatic index, Gonadotropins, Somatolactin.

\footnotetext{
${ }^{1}$ Departamento de Biodiversidad y Biología Experimental. Facultad de Ciencias Exactas y Naturales. Universidad de Buenos Aires, ciudad Universitaria, C1428EHA Buenos Aires, Argentina. pandolfi@bg.fcen.uba.ar (corresponding author)

${ }^{2}$ Departamento de Fisiologia, Instituto de Biociências (USP). Rua do Matão, Travessa 14, 321, sala 220, cidade Universitária, 05508-900 São Paulo, SP, Brazil.
} 


\section{Introduction}

Among social animals, dominance can have long-term physiological consequences. There are strong interactions between behavior, the endocrine and nervous systems that affect the interactions between an animal and its environment, including social interactions. For example, dominance status has been shown to control fertility (Fraley \& Fernald, 1982; Abbot et al., 1998; Faulkes \& Bennet, 2001), suppressing gonadal maturation in subordinate individuals (Barret et al., 1990), and also influence on neurogenesis (Kozorovitskiy \& Gould, 2004), growth rate (Hofmann et al., 1999), and stress (Fox et al., 1997; Abbot et al., 2003). Although social regulation on several physiological processes is a well-established phenomenon, little is known about the mechanisms linking the social environment to physiological changes associated with dominance. Fox et al. (1997) found that the level of the stress hormone cortisol depends critically on both the social and reproductive status of an individual fish and on the stability of its social situation.

Many teleost fish exhibit a wide range of behavioral responses to environmental and social stimuli, which are quite often associated with their reproduction. Reversible changes in reproductive competence, adoption of distinct reproductive strategies within one sex, and reversible or permanent changes in gonadal sex are examples of the influence of the behavior on the reproduction (Ross, 1990; Taborsky, 1994). In this context, cichlids (Perciformes: Cichlidae) have been intensively used as experimental models for studies of social control of reproduction, in particular African cichlids, such as the African tilapia Astatotilapia burtoni (Günther, 1894) (= Haplochromis burtoni) and Oreochromis mossambicus (Peters, 1852) (Fox et al., 1997; Ogawa et al., 2006). Behavior of African cichlids is better characterized than the Neotropical cichlids, and most of whose species have not been extensively studied at the behavioral level. Although the Convict cichlid, Amatitlania nigrofasciata (Günther, 1867) from Central America is the most studied species at the behavioral level (Noonan, 1993; Nuttal \& Keenleyside, 1993; Wisenden, 1995), South American cichlids have not been studied yet with respect to the physiological processes triggered by different behavior responses, and also regarding the intraspecific social interactions effects on reproduction. Cichlasoma dimerus (Heckel, 1840) is a South American cichlid that easily adapts to aquarium conditions and spawns with high frequency (every 15 days approx.) during 6 months of the year under natural conditions and throughout the year in the laboratory under long photoperiod $(14 \mathrm{~h})$ and controlled temperature $\left(20-26^{\circ} \mathrm{C}\right)$. Due to these advantageous characteristics, $C$. dimerus is becoming an interesting model for reproductive and developmental studies (Pandolfi et al., 2009). In addition, C. dimerus displays an elaborate social system and complex, relatively stereotyped breeding activities, which make this species very suitable for studies of intraspecific social interactions on reproduction.

The aim of this study is to describe social and reproductive behavior of $C$. dimerus under laboratory conditions. Based on the hypothesis that non reproductive individuals may be inhibited at some level of the hypothalamic-pituitary-gonadal axis, we have evaluated reproductive parameters, such as gonadosomatic index, plasma cortisol levels and pituitary hormones content ( $\beta$-LH and $\beta$-FSH semiquantification) within the different social statuses of $C$. dimerus. In addition we have analyzed body color and somatolactin (SL) pituitary content within the different social statuses. Previous studies on this species and in the Red Drum (Sciaenops ocellatus) showed an effect of SL on body color background adaptation (Zhu \& Thomas, 1996; Cánepa et al., 2006). Also, between resting and sexually active females of Pejerrey (Odonthesthes bonariensis) differences were found in the area of immuno reactive (IR) SL cells, and also a positive correlation between the ir-SL cellular area and the gonadosomatic index. In males, this correlation was not found (Vissio et al., 2002). Preliminary observations in C. dimerus showed differences in body color related to different social status. Therefore, we decided to monitor body color in relation to different social status and also measure pituitary SL content.

\section{Material and Methods}

\section{Animals}

Cichlasoma dimerus caught in Esteros del Riachuelo: $27^{\circ} 35^{\prime} \mathrm{S} 58^{\circ} 45^{\prime} \mathrm{W}$ (Corrientes, Argentina) were housed in aquaria under conditions mimicking their natural habitat (Casciotta et al., 2005; Alonso, pers. observ.) for at least one month before starting the experiments. The conditions were $25 \pm 1^{\circ} \mathrm{C} ; 14$ : 10 light: dark cycle with full spectrum illumination. A layer of gravel $(\sim 4 \mathrm{~cm})$ covered the bottom of the aquaria and natural aquatic plants (Cabomba sp., Ceratopteris spp., Echinodorus sp., and Egeria densa) were placed together with stones that fish use to delimit their territories and lay their eggs. Animals were fed ad libitum every morning with cichlid pellets (Tetra). All the experiments were conducted in accordance with international standards on animal welfare as well as being compliant with local and national regulations. Procedures are in compliance with the National Institutes of Health Guide for Care and Use of Laboratory Animals (NIH publication no. 85-23, revised in 1985). In some experiments, when aggressive interactions appeared to be excessive, the animals were separated to avoid injuries.

\section{Experimental design}

Under controlled conditions of temperature and photoperiod described above 4 females and 4 males of $C$. dimerus, size matched, were kept in an aquarium (density = 50 individuals/square $\mathrm{m}$ ) with an internal mechanical filter. The aquaria was divided in the middle by a barrier of rocks and plants and it had two flat dark stones over the gravel, one on each side $(C$. dimerus has a preference for this kind of surface for laying their eggs) (Fig. 1). Animals were observed daily for periods of at least $15 \mathrm{~min}$ in the morning and in the afternoon to verify social status, color pattern and general 


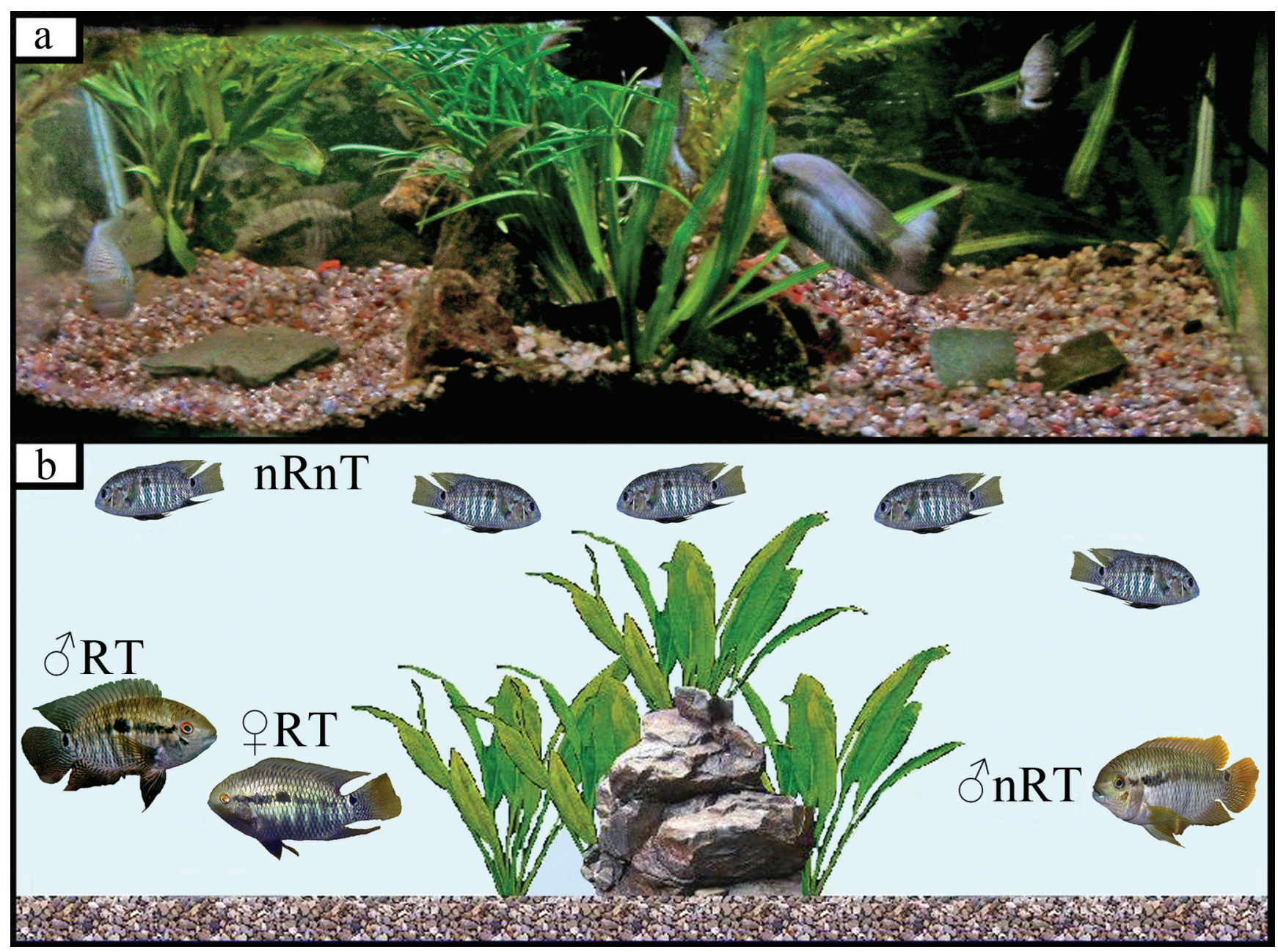

Fig. 1. Distribution of different social status fish on the experimental aquaria: a) Picture of the experimental aquaria; b) Schematic representation. Abbreviations of social statuses used: $\mathrm{nRnT}=$ non Reproductive non Territorial individuals; $\mathrm{nRT}=$ non Reproductive Territorial individual; $\mathrm{RT}=$ Reproductive Territorial individual. For a detailed description of these social statuses see Table 3 .

behavior. The establishment of territories, social dominance hierarchies, and reproductive behavior were observed. Larvae hatched from eggs two days after fertilization, and started to swim eight days after fertilization (Meijide \& Guerrero, 2000). When the most aggressive interactions between the dominant pair and the subordinate individuals were registered, we expected to find the most significant physiological differences among the groups. Therefore, animals were sacrificed 8 days post-spawning of the reproductive pair (RTm and RTf).

Only 4 out of the total 8 fish in each aquarium were sampled at the end: 1 dominant pair ( 1 male and 1 female, Reproductive Territorial [RT] individuals), and 2 subordinate individuals (1 non Reproductive non Territorial [nR-nT] male and $1 \mathrm{nR}-\mathrm{nT}$ female) were sacrificed per experiment. The $n R-n T$ individuals used here were always those ones in the lowest position in the social hierarchy. The animals were anesthetized by immersion in a $0.1 \%$ benzocaine solution. Animals were weighed and standard length measured. Blood samples were taken to measure cortisol plasma levels and afterwards animals were sacrificed by decapitation. Testes were weighed to determine the gonadosomatic index. Pituitaries were processed as described below for Western blot analysis. The experiment was repeated 4 times ( 4 replicates) using a total of 32 individuals $(\mathrm{N}=4 ; \mathrm{n}=32)$.

\section{Plasma cortisol measurement}

Blood was drawn from fish immediately after capture (less than $4 \mathrm{~min}$ ) by caudal puncture and stored in heparinized tubes to allow it to clot. Then, serum was separated by centrifuging the samples at $3000 \mathrm{rpm}$ for $20 \mathrm{~min}$ and stored at “ $-20^{\circ} \mathrm{C}$ until assay. Cortisol was measured by ECLIA (electrochemiluminescence immunoassay) using a Cobas analyzer (Roche).

\section{Semiquantification of $\beta$-FSH, $\beta$-LH, and SL pituitary content}

In order to semi-quantify pituitary content of hormones related to reproduction ( $\beta$-FSH, $\beta$-LH and) and background color adaptation (SL), an analysis with 15\% sodium 
dodecylsulfate-polyacrylamide gel electrophoresis (SDSPAGE) followed by Western blot was performed. The hormones were detected using heterologous antisera, the specificity of which had been previously tested in this species (Pandolfi et al., 2001, 2006) (Table 1). After dissection, each pituitary was homogenized in $100 \mathrm{ml}$ of Tris-HCl buffer $50 \mathrm{mM}$, $\mathrm{pH} 7.4$, with $1 \mu$ l of protease inhibitor cocktail (Sigma, St Louis, Mo.). Then, $15 \mathrm{mg}$ of protein with loading buffer $(120 \mathrm{mM}$ Tris-HCl pH 6.8, 3\% dodecylsulfate, $10 \%$ glycerol, $1 \% \beta$ mercaptoethanol) were heated at $100^{\circ} \mathrm{C}$ for 5 min and loaded into the SDS-PAGE. After electrophoresis, proteins and molecular markers (SeeBlue Plus2 PreStained Standard; Invitrogen) were transferred to a nitrocellulose membrane (Amersham Biosciences) for $60 \mathrm{~min}$ at $4^{\circ} \mathrm{C}$ and $75 \mathrm{~V}$. Then, membranes were washed in Tris Buffer Saline Tween20 (TBST) pH 7.5 and blocked with TBST containing 3\% non-fat dry milk overnight. After that, they were incubated for $3 \mathrm{~h}$ at room temperature (RT) with different primary antisera (Table 1) and washed in TBST afterwards. Membranes were then incubated with a biotinylated anti-rabbit IgG (Sigma-Aldrich) (1:1000) for $1 \mathrm{~h}$ at RT, washed again and finally incubated with a streptavidin complex conjugated to alkaline phosphatase (Sigma-Aldrich) (1:2000) for $45 \mathrm{~min}$ at RT. After washing, the reaction was visualized using an alkaline phosphatase developing kit (BCIP/NBT, Vector Blue, Dako). Finally, membranes were dried, digitalized and optical density semiquantification was performed using Image Gauge version 3.12 (Fuji Photo Film) software. In order to avoid a possible loading error in the SDS-PAGE, pituitary hormone content was semiquantified by densitometric analysis and normalized to the optical density obtained for $\alpha$-tubuline.

\section{Statistical analysis}

Statistical analysis of cortisol data was performed using a three factor analysis of variance (ANOVA), with two fixed factors: sex and reproductive state; and one random factor: experiment repetition. This design allowed us to test for interactions between sex and reproductive state and also to control some experimental error regarding to variability among experiment repetition. Statistical analysis of organ-somatic index was performed by using Student's t-test. Statistical analysis of Western blot data was performed using the MannWhitney test. All suppositions for these statistical analyses were tested. Statistical significance was established at the $\mathrm{p}<0.05$ level for all tests. Data was presented as means \pm SEM. Statistica 7.0 Software (Statsoft, Inc) was used for analysis.

\section{Results}

We observed that the commonly used categories of "Dominant" and "non-Dominant" commonly used for the social status of individuals were not suitable for $C$. dimerus because dominance in this species seems to be linear $(\mathrm{A}>\mathrm{B}>\mathrm{C}>\mathrm{D} \ldots)$ rather than despotic $(\mathrm{A}>\mathrm{B}=\mathrm{C}=\mathrm{D} \ldots)$. For example, A would be dominant with respect to $\mathrm{B}, \mathrm{C}$, and $\mathrm{D}$ and $\mathrm{B}$ is dominant with respect to $\mathrm{C}$ and $\mathrm{D}$ but also is a subordinate
Table 1. Antisera used in the Western blot analysis and estimated molecular mass of Cichlasoma dimerus pituitary hormones. ${ }^{1}$ Departamento de Bioquímica y Biología Molecular, Facultad de Ciencias, Universidad de Cádiz, Spain; ${ }^{2}$ National Research Institute of Fisheries Science. Fisheries Research Agency. Kanazawa, Yokohama, Japan.

\begin{tabular}{lcllr}
\hline Antisera & Dilution & \multicolumn{1}{c}{ Source } & Donated from & $\begin{array}{r}\text { Detected } \\
\text { ir-band/s }\end{array}$ \\
\hline anti-SL & $1: 2000$ & Sparus aurata & Antonio Astola $^{1}$ & $32 \& 28 \mathrm{kDa}$ \\
anti- $\beta$ FSH & $1: 1000$ & Fundulus heteroclitus & Akio Shimizu $^{2}$ & $19 \& 15 \mathrm{kDa}$ \\
anti- $\beta$ LH & $1: 2000$ & Fundulus heteroclitus & Akio Shimizu $^{2}$ & $24 \mathrm{kDa}$ \\
\hline
\end{tabular}

to A. This ambiguity made these categories not adequate to describe the different social status observed in C. dimerus. Therefore, we propose new categories that better explain the social status observed, based on the reproductive state and territoriality of individuals (Table 2).

\section{Sexual dimorphism}

Although there are no conspicuous external morphological differences observed between males and females, in general C. dimerus males are larger than females (10 $\mathrm{cm}$ and $49 \mathrm{~g} v s .8 \mathrm{~cm}$ and $32 \mathrm{~g}$ respectively; standard length (SL) and mass). Mean female sl is about $84 \%$ that of males. The larger males ( $\mathrm{SL}>9 \mathrm{~cm}$ ) sometimes present some of the posterior dorsal fin rays elongated and curved, in hooked shape to the posterior margin of the fin. These elongate rays often extended beyond the caudal fin distal margin as seen in the male of Fig. 2e. Remarkably, some males, especially smaller ones ( $\mathrm{SL}<9 \mathrm{~cm}$ ), do not have this curved margin (Fig. 2c) and some females can also have relatively elongated dorsal fin rays (Fig. 2d), but the posterior end of the dorsal fin never has the hooked shape described above. Nevertheless, sexes could be differentiated during the spawning period by their distinct body color patterns and the external morphology of the genital papillae, which was thinner and ending in a point in males $v s$. wider and blunt in females.

Table 2. Dominance and social statuses in Cichlasoma dimerus.

\begin{tabular}{|l|l|}
\hline & SOCIAL STATUS \\
\hline & Gregarious \\
\hline D & RT= Reproductive Territorial \\
O & \\
I & \\
N & nRT= non Reproductive Territorial \\
A & \\
C & nRnT= non Reproductive \\
E & non Territorial \\
\hline
\end{tabular}



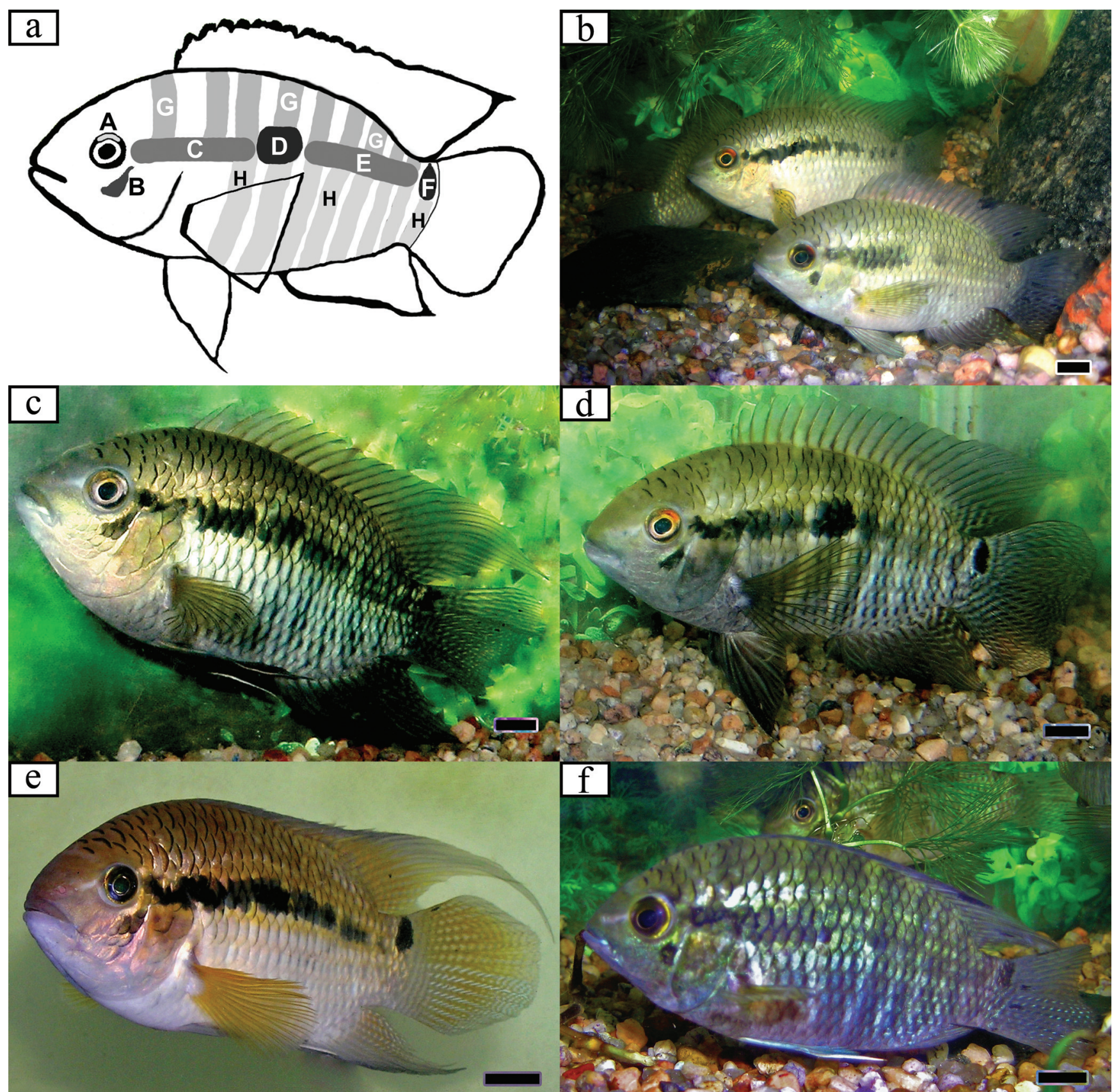
Table 3. Description of body color patterns observed in different social statuses. Territorial individuals have a bright background color, meanwhile non territorial presents dark background color. Also, reproductive individuals show a darkening of ventral body region, as opposed to the whitish ventral region in gregarious ones.

\begin{tabular}{ll}
\hline Sregarious & $\begin{array}{l}\text { Pale background color. Grayish dorsal region and whitish ventral region. Transverse stripes may be present but always grey and } \\
\text { not very conspicuous. }\end{array}$ \\
$\begin{array}{l}\text { Reproductive- } \\
\text { Territorial male } \\
\text { (RT male) }\end{array}$ & $\begin{array}{l}\text { Bright background color may vary from blue, green to yellow. Ventral region and anal fin dark grey. Pectoral fin black. Head } \\
\text { ventral portion, below mouth and the opercle section, dark grey. Transverse ventral stripes dark, especially those in the posterior } \\
\text { prespawning period. }\end{array}$ \\
$\begin{array}{ll}\text { Reproductive } \\
\text { Territorial female } \\
\text { (RT female) }\end{array}$ & $\begin{array}{l}\text { Similar to RT male, although bright background color is generally green and the ventral portion and pectoral fin darkening is } \\
\text { generally more conspicuous, especially that of the opercles. This last difference is more evident in the prespawning period, when } \\
\text { the female is darker than its mate. }\end{array}$ \\
$\begin{array}{l}\text { Non reproductive- } \\
\text { Territorial } \\
\text { (nRT) }\end{array}$ & $\begin{array}{l}\text { Bright background color, similar to the Reproductive individuals (R), although generally not as bright. Differ from R color pattern } \\
\text { by not showing the characteristic ventral and anal and pectoral fin darkening. Transverse stripes not conspicuous, may not be } \\
\text { Non reproductive- }\end{array}$ \\
$\begin{array}{l}\text { present. } \\
\text { non Territorial } \\
\text { (nRnT) }\end{array}$ & \begin{tabular}{l} 
Dark grey background color. Transverse stripes always present. Bright colors never present. \\
\hline
\end{tabular}
\end{tabular}

animals started to show explorative and active behavior and many aggressive interactions were observed, which we classified into two types: 1) physical contact and 2) threatening displays (Table 4, Fig. 3).

Physical interactions (Fig. 3) were generally preceded by threatening displays, especially during establishment of territories and social hierarchies. All these aggressive interactions resulted in a social hierarchy which starts with the territorial delimitation by the most dominant male. In the given experimental conditions, the largest male chose a territory close to the gravel substrate limited horizontally by stones or plants and aggressively defended it from other fish. These males were defined as Reproductive-Territorial male (RTm) (Fig. 1), showing a characteristic body coloration patter as described above (Fig. 2c). The female mate of this male was called Reproductive Territorial females (RTf) (Fig.1). At the same time another male defended a territory on the substrate on the opposite side of the aquarium. This male defended its territory from other subordinate fish but was continuously attacked by the dominant pair (RTm and RTf) and did never reproduce. This animal was called as non reproductive-Territorial male (nRTm) and it was easily recognizable not only by its position in the aquarium but also from its body coloration pattern (Fig. 2d). Individuals that could not defend a territory were considered as non Reproductivenon Territorial (nR-nT). They were observed hiding between the floating plant roots and displayed a characteristic dark color pattern (Fig. 2e) and fin retraction. nRT males and nT-nD individuals showed submission displays, such as escape and fin retraction, towards dominant individuals.

\section{Reproductive behavior: Prespawning}

Several days after fish were transferred to the experimental aquarium, territories were progressively established. In Fig. 1 a schematic distribution of the different social status individuals in the experimental aquarium is shown. The dominant male aggressively defended the prospective spawning site, which is usually a flat stone on the gravel.
They seem to prefer horizontal and smooth hard surfaces of about $100 \mathrm{~cm}^{2}$ or more. The male takes stones and cleans the spawning surface with its mouth and undulates its body in an "S" shaped way over the spawning surface. Some females were aggressively rejected from the territory by the male which exhibited bright background coloration (Fig. 2c). The same "threatening displays" described above were also performed towards the females that were eventually accepted as potential mates by the male. Since only one RTm was found in our experimental design, it is still unclear if females can choose between different RTm. When the pair was formed, the Reproductive Territorial female (RTf) (Fig. 1, 2f) defended the territory with the male and both acquired a characteristic color pattern with a darkened grey body ventral region (Fig. 1g). We have also observed in all social statuses that the transverse lines darkened during the aggressive behaviors performed

Table 4. Ethogram outlining the aggressive, submissive and reproductive behavioral repertoire of Cichlasoma dimerus.

\begin{tabular}{|c|c|c|}
\hline & & Social Interactions \\
\hline & $\begin{array}{l}\text { Physical } \\
\text { Contact }\end{array}$ & $\begin{array}{l}\text { Bites } \\
\text { Tail hit } \\
\text { Mouth holding }\end{array}$ \\
\hline Aggressive & $\begin{array}{l}\text { Threatening } \\
\text { displays }\end{array}$ & $\begin{array}{l}\text { Fin erection } \\
\text { Chasing } \\
\text { Opercula opening } \\
\text { Head Shaking } \\
\text { Body Shaking }\end{array}$ \\
\hline Submissi & e Displays & $\begin{array}{l}\text { Escape } \\
\text { Fin retraction }\end{array}$ \\
\hline Reproduct & ve Displays & $\begin{array}{l}\text { Fin erection } \\
\text { Opercula opening } \\
\text { Head Shaking } \\
\text { Body Shaking } \\
\text { Stone biting } \\
\text { Wave movements over the spawning surface } \\
\text { (SF) } \\
\text { Genital papillae rubbing on the SF } \\
\text { S body shape and shaking over the SF } \\
\text { Pit digging } \\
\text { Eggs fanning } \\
\text { Pelvic fin shaking }\end{array}$ \\
\hline
\end{tabular}




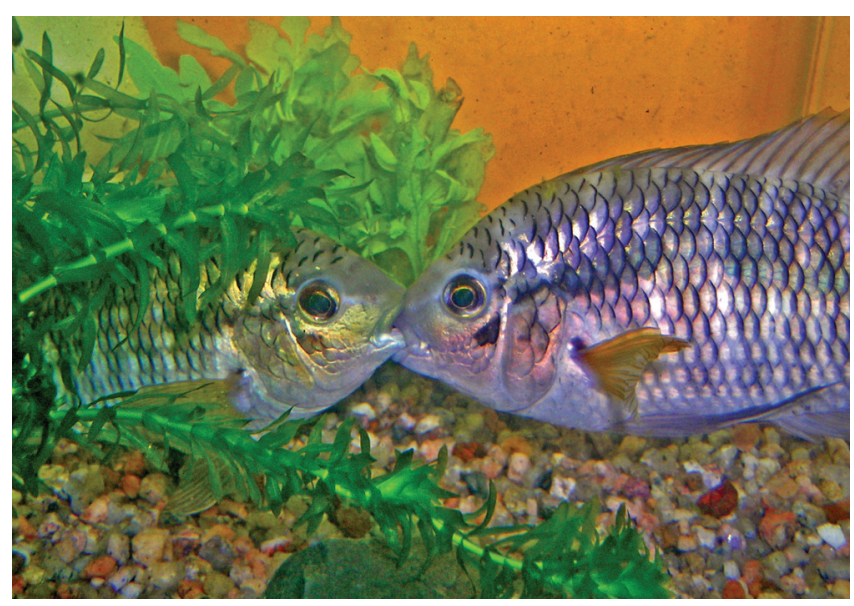

Fig. 3. Image showing aggressive physical contact between two males, referred to as mouth holding. by the individuals; probably this darkening is correlated with aggressiveness as a threatening display.

\section{Reproductive behavior: Spawning and parental care}

Cichlasoma dimerus engages in biparental care of the fry. The male and female rubbed their genital papillae over the spawning substrate and cleaned it with their mouths. The male shook over it showing its flanks to the female. The female laid adherent eggs over the spawning surface in a line of around 10 eggs and then the male passed over fertilizing them (Fig. 4a). It was observed that spawning may last up to $90 \mathrm{~min}$ and, depending on the size of the female, from 400 to 800 eggs are laid (Fig. 4b). The number of eggs which are laid may be limited by the available spawning surface. After spawning, both parents took care of the eggs by defending them from other fish and animals, attacking any intruder into their

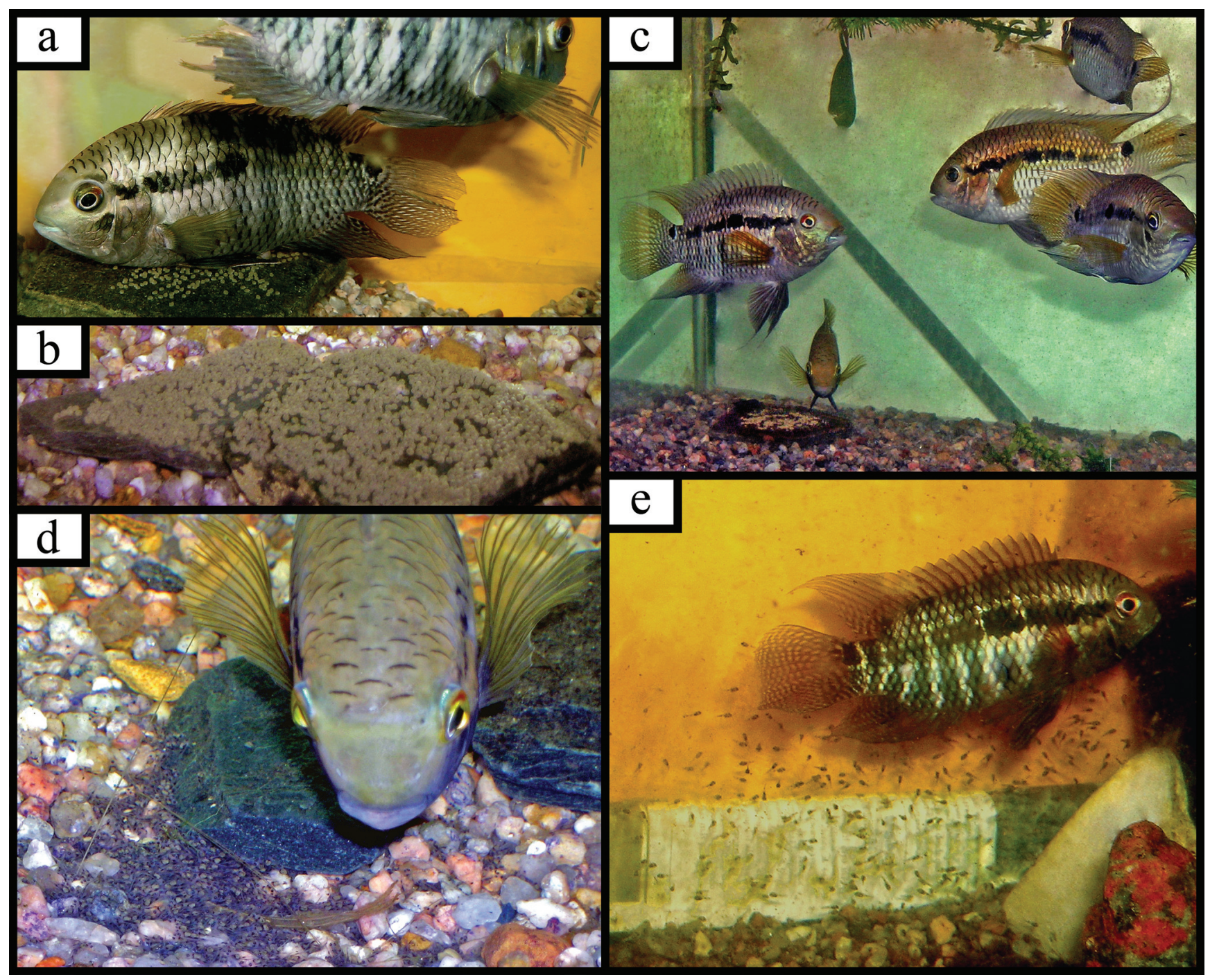

Fig. 4. Reproductive phases: a) Female laying eggs while male waits to fertilize them. This process is then repeated; b) Spawn on a flat dark stone. Generally between 400 - 800 eggs are laid, depending on female size; c) Female guarding the eggs while male attacks an intruder male. Generally one of the parents remains guarding the fry while the other feeds or defends the territory; d) Female fanning non swimming fry after transferring them to a previously dug pit; fry hatched 3 days after fertilization; e) Male guarding free swimming fry ( 8 days after fertilization); parents seem to attract the fry by shaking its dark pelvic fin. 
territory. Both alternatively fanned the eggs by beating their pectoral fin over the clutch. When one parent left the clutch for food or to attack an intruder into their territory, the other generally stayed taking care of the eggs or larvae. In consequence it was very unusual to observe fry without one of the parents taking care of them (Fig. 4c). Dead eggs, which look white and usually are attacked by fungi, are removed by the parents. Parents will start to dig in the gravel making nests of about $10-20 \mathrm{~cm}$ of diameter and $5-10 \mathrm{~cm}$ depth (Fig. 4d). Larvae started to hatch at the beginning of the third day at a water temperature of $25^{\circ} \mathrm{C}$, and were subsequently transferred by the pair to a previously dug pit. During five more days larvae remained attached to the bottom of the pit by a head adhesive-gland and both parents took care of them and transferred them to different pits. Larvae started swimming 8 days post fertilization (Fig. 4e). During this period the reproductive pair (RTm and RTf) expanded their territory size and increased their aggressiveness toward non-dominant individuals. They continually attacked the other fish during the whole period of fry care (Fig. 5). Larvae followed their parents foraging on the ground. Both parents attracted them by shaking their pelvic fin that showed a dark grey color at this stage. This behavior was especially observed when there was a perturbation near the aquarium. As described herein, the same dark color was also observed in the trunk and head ventral region in both parents. Animals were sacrificed at this stage.

\section{Male gonadosomatic indexes}

Gonadosomatic indexes did not show significant differences between Reproductive $(0.18 \pm 0.047)$ and non Reproductive males $(0.10 \pm 0.015)$.

\section{Plasma cortisol levels}

Non Reproductive males and females (nR-nT) had significantly higher cortisol levels than Reproductive males and females respectively. Also, males showed higher cortisol levels than females (Fig. 6).

\section{Pituitary hormone content}

The relative optical density of ir- $\beta$-FSH, $\beta$ - $\mathrm{LH}$, and SL bands (normalized to $\alpha$-tubuline) was measured in order to test the hypothesis that the social status affects the pituitary content of these hormones. The analysis showed that $\mathrm{R}$ males had significantly higher pituitary content of $\beta$-FSH and SL than $\mathrm{nR}$ males (Fig. 7a), while no significant differences were detected in $\beta$-LH pituitary content. In females, no significant differences were found in the pituitary content for any measured hormone (Fig. 7b).

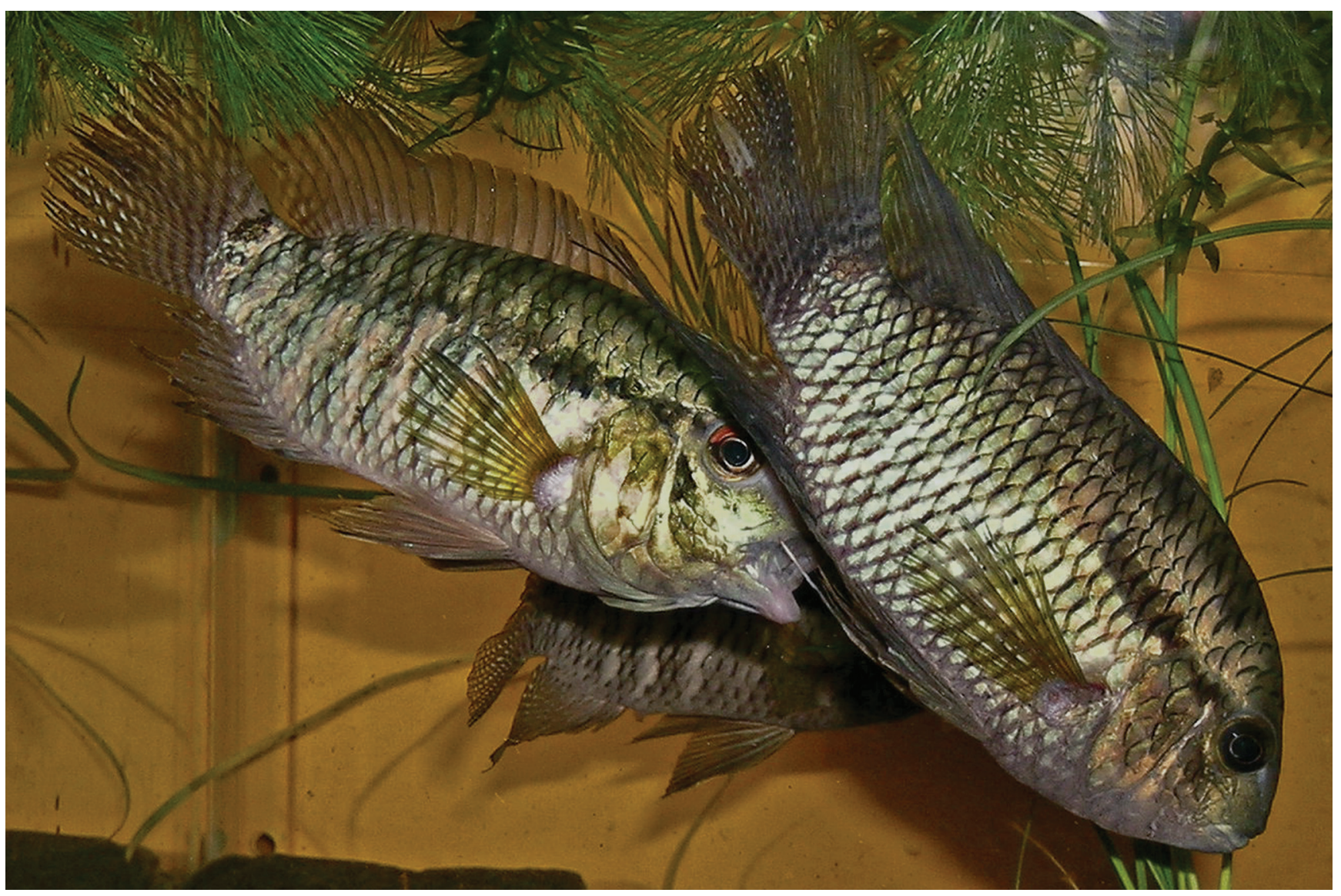

Fig. 5. Reproductive territorial male attacking a non reproductive territorial male. 


\section{Discussion}

We described for the first time $C$. dimerus social and reproductive behavior in the laboratory, including the establishment of dominance hierarchy. We also characterized the different social statuses and body coloration patterns associated with them.

During the cold, short-photoperiod season, C. dimerus do not reproduce and shows the gregarious behavior and color pattern described in the results section. In this species, short photoperiod reduces male aggression either related to territory selection or its defense, and also females under this photoperiod are never chosen as mates by the males (Fiszbein et al., 2010). This indicates that short photoperiod inhibits reproductive behavior and, in consequence, diminishes aggressiveness. Social hierarchies are not maintained during this season and almost no aggressive interactions are observed (Alonso, pers. observ.).

The start of the warm, long-photoperiod season is followed by the social interactions that determine the social hierarchy among the individuals of this species. Size is the most important factor in the establishment of social hierarchy, probably being related to strength, which is supported by the observation that hierarchies are established by aggressive interactions, including physical contact. All threatening displays have the common effect to make the fish seem "as larger as possible" by maximizing the visible area. This could be related to size, which in turn may be a good indicator of

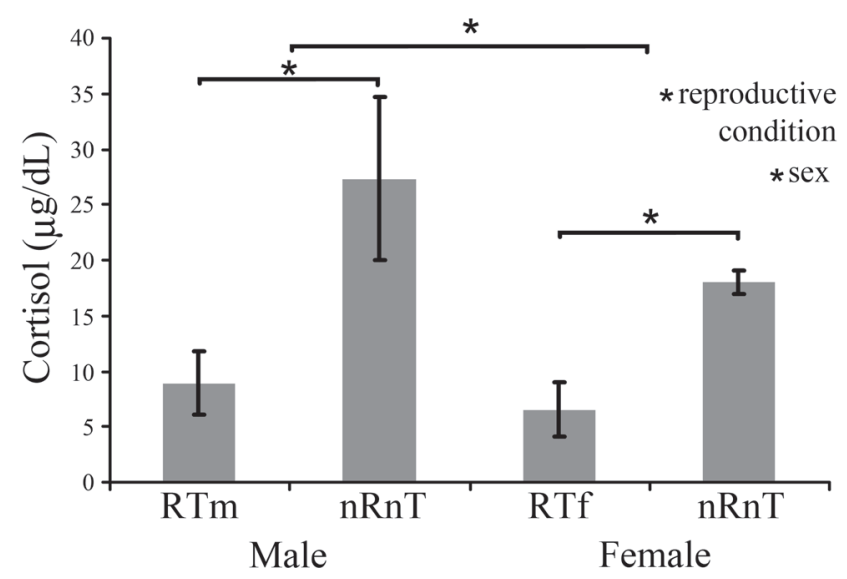

Fig. 6. Plasma cortisol levels in reproductive territorial (RT) and non reproductive non territorial (nRnT) males and females $(\mathrm{N}=4)$. Cortisol levels were higher in males than females. Non Reproductive individuals presented higher levels than reproductive ones for both sexes $(p<0,05)$. No significant interaction was detected between sex and reproductive state. A three factor ANOVA was performed to analyse this data, with experiment repetition as a random factor. Asterisks indicate a statistical difference at $\alpha=0.05$ for the factor sex (male $v s$. female) and reproductive condition (reproductive $v s$. non reproductive). strength and would explain why in our experiments the most dominant male, which is reproductively active, was always the largest male in the aquarium. In the convict cichlid, Amatitlania nigrofasciata, females show no preference based on male reproductive experience or dominance status, but prefer the largest between two males (Noonan et al., 1983; Gagliardi-Seeley et al., 2009). Male convict cichlids have been shown to prefer gravid over non gravid females, and to prefer the largest between two gravid females (Nuttal \& Keenleyside, 1993). In free-ranging fish, it was observed that breeding fish paired up according to size; large males with large females and small males with small females. Small males and, in some
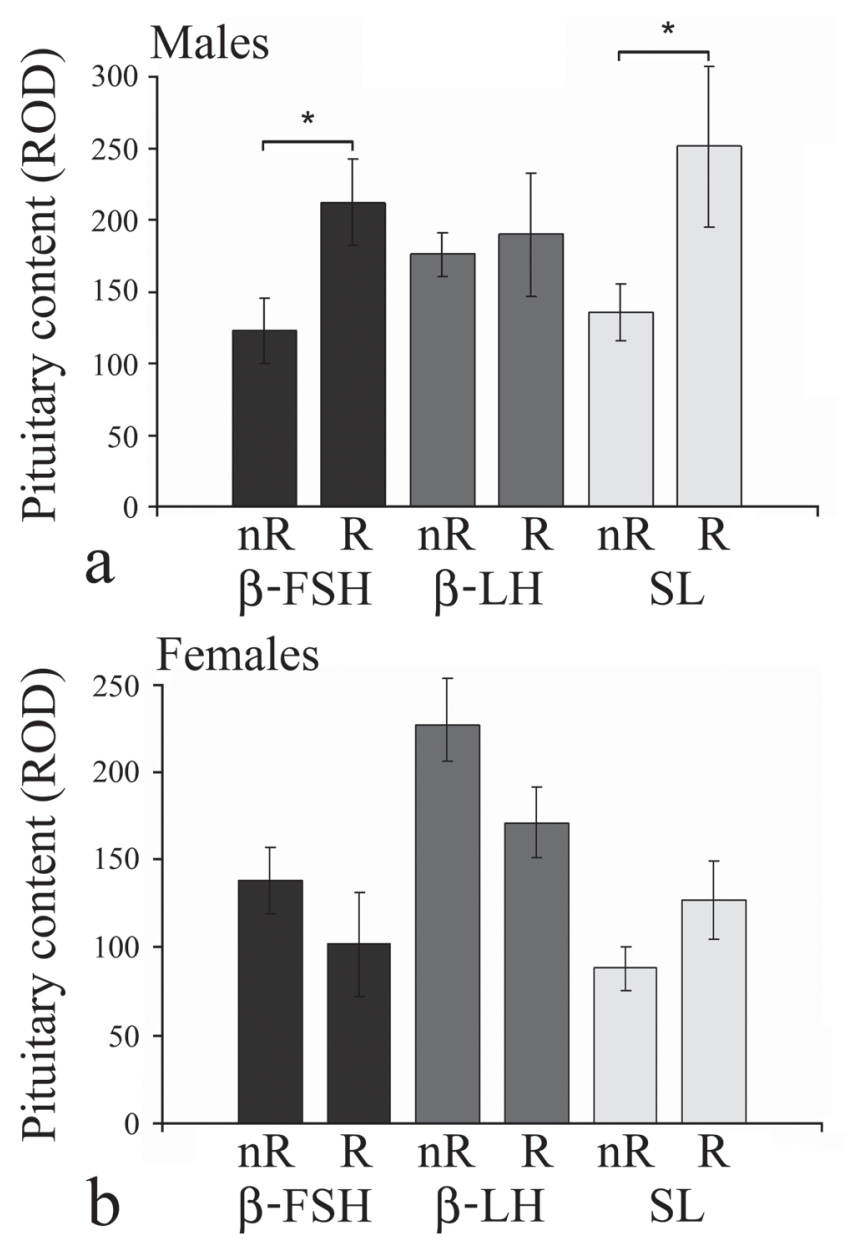

Fig. 7. Semiquantitative analysis of pituitary hormone content from reproductive $(\mathrm{R}) v s$. non reproductive $(\mathrm{nR})$ individuals $(n=4)$. Values are expressed in arbitrary units (a.u.) as means \pm SEM and normalized to $\alpha$-tubuline. $\mathrm{ROD}=$ relative optical density. Asterisks indicate a statistical difference at $\alpha=0.05$ with a Mann-Whitney test. a) Males: Greater pituitary $\beta$-FSH and SL content was observed in R males compared to $n R$ males $(\mathrm{p}<0.05)$. No significant differences were observed in $\beta$-LH pituitary content between R and NR males. b) Females: No significant differences were observed in $\beta$-LH, $\beta$-FSH, and SL pituitary content between $\mathrm{R}$ and $\mathrm{nR}$ females. 
cases, small females were excluded from breeding (Wisenden, 1995). An outstanding feature of C. dimerus behavior is that the threatening displays were the same displays performed towards females accepted as potential mates by the male. These intra-sexually selected behavioral features were probably reinforced by inter-sexual selection (reviewed in Anderson, 1994) because these are good predictors of male size and selecting these features would positively correlate with a better fitness for females. This would also account for males being larger than females, given that this feature may have evolved through inter and intra-sexual selection.

As observed in C. dimerus, convict cichlid females, despite selecting one male over another male early in the courtship period, continue to visit both males until spawning. It was suggested that this assessment behavior would more closely resemble a bet-hedging tactic rather than female's indecision. Higher aggressiveness in males than females during the prespawning period was also observed, and females invested more time than males on parental care (Gagliardy-Seeley et al., 2009). As in Amphilophus citrinellus (Rogers, 1987), C. dimerus males showed more aggressiveness toward other males than toward females.

In Cichlasoma dimerus those individuals that acquire reproductive territories adapts their physiology to reproduction and show the bright background body color pattern, as opposed to the dark color pattern of nRnT, which is probably a submissive display. In the convict cichlid, sexual dichromatism was shown to affect intrasexual aggression among females (Beeching et al., 1998). Those fish lower in the social hierarchy that not obtained reproductive territories searched for refuge under the leaves of plants and aggressively defended this position from subordinate individuals in the social hierarchy. The maintenance of the dominance hierarchy among non-reproductive individuals may be related not only to access to resources such as food (i.e., Arthropoda living in between plants) and refuge, but also may eventually determine access to new available reproductive territories due to death of reproductive individuals, or environmental changes such as flooding of nearby areas, for example.

The fast changes in body color pattern of these fish allow them to have a complex and effective signaling system capable of sending complex information quickly and reinforcing that visual cues are very important in fish communication. This feature of their visual communication may have a positive adaptive value by permitting a faster adaptation to changes in dominance status and life in a variable environment. Changes in the dark stripes, lines and body blotches were quick, suggesting that these changes were probably mainly controlled by nervous system, although background coloration changes are long term adaptations and so are more likely to have mainly an endocrine control.

Similarities between behaviors of different Neotropical cichlids may indicate that some of these behavioral patterns were well conserved during the evolution of this lineage or converged due to similar selective pressures related to life in similar environments. However, the former hypothesis may be the more parsimonious because there are many other similar features among these fishes such as color pattern (i.e., bright in reproductive dominant individuals, dark stripes). For a better comprehension of the evolution of behavior and reproductive physiology in cichlids phylogenetic studies that include independent comparisons should be done.

In the African cichlid Astatotilapia burtoni, (= Haplochromis burtoni) territorial males develop their coloration patterns faster, weigh more and have larger and more developed gonads than non-territorial males (Fernald, 2002). In established groups of the highly territorial groupliving African cichlid Neolamprologus pulcher, dominant individuals have higher androgen levels and greater relative gonad investment than the subordinates ones (Fitzpatrick et al., 2006; Desjardins et al., 2008) but plasma androgen levels did not correlate with relative gonad investment in females or males, winners or losers after territory competition (Taves et al., 2009). Considering the experimental design of the present work, in C. dimerus no differences were found between GSIs of RT and nRnT males. This could be related to the short-term nature of the study that probably precluded any difference related to social status and gonadal investment. Also, the fact that dominant males were sacrificed 8 days postspawning/spermiation may have resulted in a low GSI values for these individuals. Since the reproductive opportunities may occur at any time during the reproductive period, it would have a positive adaptive value for $\mathrm{nR}$ individuals to always be ready for reproduction during this period.

The fact that different cortisol levels are related to social status in $C$. dimerus indicates that social statuses represent different levels of stress. In both sexes, $\mathrm{nRnT}$ individuals had higher serum cortisol than RT ones. In A. burtoni it was clearly demonstrated that $\mathrm{nT}$ males had more plasma cortisol levels than $\mathrm{T}$ ones, but this is also highly dependent on community conditions and length of time in these conditions (Fox et al., 1997; White \& Fernald, 1997). In C. dimerus cortisol may serve as an endogenous signal relating the social environment to the social status of the animal, behavior and internal reproductive state. Physical contact aggressions from the $\mathrm{R}$ individuals towards $\mathrm{nR}$ ones may inhibit the signals that trigger reproduction by increasing cortisol levels, excluding therefore these individuals from competition and leaving more resources available for the reproductive pair and their fry. Submissive displays may be more likely to occur in fish with high cortisol levels, with the positive adaptive value of diminishing attacks by dominant individuals. The higher cortisol plasma levels observed in males when compared to females may be due to males showing greater aggressiveness, which was qualitatively observed. Experimental manipulation of serum cortisol levels and behavioral experiments should be performed to address these issues.

In $C$. dimerus the lower levels of $\beta$-FSH pituitary content in $\mathrm{nR}$ males, compared to $\mathrm{R}$ ones, may indicate an inhibition of $\beta$-FSH synthesis and/or secretion. This could be due to an inhibition, via plasma cortisol, of GnRH-1 synthesis or 
release. However, we could not rule out an effect on the onset of spermatogenesis in RT males considering that they were sampled 8 days after spermiation. The higher levels of SL pituitary content in RT males could be related to body background color changes related to territory defense, reproduction and parental care. It was previously seen in this species that animals adapted to black background showed a darker background body color and higher SL pituitary content than animals adapted to white background (Canepa et al., 2006). Also, differences found in SL related to the reproductive state of females of the pejerrey Odonthestes bonariensis (Vissio et al., 2002) could be related to differences in body color rather than a direct influence on the reproductive axis. No significant differences in $\beta$-FSH, $\beta$-LH, and SL pituitary content between RT female and nRnT females were found.

Further studies will be necessary to understand the factors that affect the establishment of social hierarchies and the dynamics of social status. In order to achieve a better understanding of the reproductive system of this species, future studies should focus on the physiological mechanisms underlying the reproductive inhibition due to high cortisol levels of the individuals lower in the social hierarchy. Also sexual selection experiments, together with field observations on the natural habitat of $C$. dimerus should be performed.

\section{Acknowledgements}

We specially thank to two anonymous reviewers for their pertinent comments and suggestions that helped to improve the manuscript. This work was supported by the following grants: PICT 75 (Agencia de Promoción Científica y Técnica), UBACyT X-628 (Universidad de Buenos Aires) and PIP 0020 (Consejo Nacional de Investigaciones Científicas y Técnicas).

\section{Literature Cited}

Abbott, D. H., E. B. Keverne, F. B. Bercovitch, C. A. Shively \& S. P. Mendoza. 2003. Are subordinates always stressed? A comparative analysis of rank differences in cortisol levels among primates. Hormones and Behaviour, 43: 67-82.

Abbott, D. H., W. Saltzman, N. J. Schultz-Darken \& P. L. Tannenbaum. 1998. Adaptations to subordinate status in female marmoset monkeys. Comparative Biochemistry and Physiology Part C: Pharmacology, Toxicology and Endocrinology, 119: 261274.

Anderson, M. 1994. Sexual selection. Princeton University Press, Princeton, NJ.

Barrett, J., D. H. Abbott \& L. M. George. 1990. Extension of reproductive suppression by pheromonal cues in subordinate female marmoset monkeys, Callithrix jacchus. Journal of Reproduction and Fertility, 90: 411-418.

Beeching, S. C., S. H. Gross, H. Bretz \& E. Hariatis. 1998. Sexual dichromatism in convict cichlids: the ethological significance of female ventral coloration. Animal Behaviour, 56: 1021-1026.

Cánepa, M. M., M. Pandolfi, M. C. Maggese \& P. G. Vissio. 2006. Involvement of Somatolactin in background adaptation of the cichlid fish Cichlasoma dimerus. Journal of Experimental Zoology, 305: 410-419.

Casciotta, J. R., A. E. Almirón \& J. Bechara. 2005. Peces del Iberá - Hábitat y Diversidad. Grafikar, La Plata, Argentina; UNDP, Fundación Ecos, UNLP y UNNE, 244p.

Desjardins, J. K., K. A. Stiver, J. L. Fitzpatrick, N. Milligan, G. J. van Der Kraak \& S. Balshine. 2008. Sex and status in a cooperative breeding fish: behavior and androgens. Behavioral Ecology and Sociobiology, 68: 785-794.

Faulkes, C. G. \& N. C. Bennett. 2001. Family values: Group dynamics and social control of reproduction in African molerats. Trends in Ecology \& Evolution, 16: 184-190.

Fernald, R. D. 2002. Social regulation of the brain: sex, size and status. Novartis Foundation Symposium, 244: 169-84; discussion 184-6, 203-6, and 253-7.

Fiszbein, A., M. Cánepa, G. Rey Vazquez, M. C. Maggese \& M. Pandolfi. 2010. Photoperiodic modulation of reproductive physiology and behaviour in the cichlid fish Cichlasoma dimerus. Physiology and Behaviour, 99: 425-432.

Fitzpatrick, J. L., J. K. Desjardins, K. A. Stiver, R. Montgomerie $\&$ S. Balshine. 2006. Male reproductive suppression in the cooperatively breeding fish Neolamprologus pulcher. Behavioral Ecology, 17, 25-33.

Fox, H. E., S. A. White, M. H. F. Kao \& R. D. Fernald. 1997. Stress and dominance in a social fish. Journal of Neurosciences, 17: 6463-6469.

Fraley, N. B. \& R. D. Fernald. 1982. Social control of developmental rate in the African cichlid fish, Haplochromis burtoni. Journal of Comparative Ethology, 60: 66-82.

Gagliardi-Seeley, J., J. Leese, N. Santangelo \& M. Itzkowitz. 2009. Mate choice in female convict cichlids (Amatitlania nigrofasciata) and the relationship between male size and dominance. Journal of Ethology, 27: 249-254.

Hofmann, H. A., M. E. Benson \& R. D. Fernald. 1999. Social status regulates growthrate: Consequences for life-history strategies. Proceedings of the National Academy of Sciences of the United States of America, 96: 14171-14176.

Kozorovitskiy, Y. \& E. Gould. 2004. Dominance hierarchy influences adult neurogenesis in the dentate gyrus. Journal of Neurosciences, 24: 6755-6759.

Meijide, F. J. \& G. A. Guerrero. 2000. Embryonic and larval development of a substrate-brooding cichlid Cichlasoma dimerus (Heckel, 1840) under laboratory conditions. Journal of Zoology, 252: 481-493.

Noonan, K. C. 1983. Female mate choice in the cichlid fish Cichlasoma nigrofasciatum. Animal Behaviour, 31: 1005-1010.

Nuttal, D. B. \& M. H. A. Keenleyside. 1993. Mate choice by the male convict cichlid (Cichlasoma nigrofasciatum; Pisces, Cichlidae). Ethology, 95: 247-256.

Ogawa, S., G. Akiyama, S. Kato, T. Soga, Y. Sakuma \& I. S. Parhar. 2006. Immunoneutralization of gonadotropin-releasing hormone type-III suppresses male reproductive behavior of cichlids. Neuroscience Letters, 403: 201-5.

Pandolfi, M., M. M. Cánepa, F. J. Meijide, F. Alonso, C. Rey Vázquez, M. C. Maggese \& P. G. Vissio. 2009. Studies on the reproductive and developmental biology of Cichlasoma dimerus (Percifomes, Cichlidae). Biocell, 33(1): 1-18.

Pandolfi, M., F. L. Lo Nostro, A. Shimizu, A. G. Pozzi, F. J. Meijide, G. Rey Vazquez \& M. C. Maggese. 2006. Identification of immunoreactive FSH and LH cells in the cichlid fish Cichlasoma dimerus during the ontogeny and sexual differentiation. Anatomy and Embryology, 211: 355-365. 
Pandolfi, M., D. A. Paz, M. C. Maggese, M. A. Ravaglia \& P. G. Vissio. 2001. Ontogeny of immunoreactive somatolactin, prolactin and growth hormone secretory cells in the developing pituitary gland of Cichlasoma dimerus (Teleostei, Cichlidae). Anatomy and Embryology, 203: 461-468.

Rogers, W. 1987. Sex ratio, monogamy and breeding success in the Midas cichlid (Cichlasoma citrinellum). Behavioral Ecology and Sociobiology, 21: 47-51.

Ross, R. M. 1990. The evolution of sex-change mechanisms in fishes. Environmental Biology of Fishes, 29: 81-93.

Taborsky, M. 1994. Sneakers, satellites, and helpers: parasitic and cooperative behavior in fish reproduction. Advances in the Study of Behavior, 23: 1-100.

Taves, M. D., J. K. Desjardins, S. Mishra \& S. Balshine. 2009. Androgens and dominance: Sex-specific patterns in a highly social fish (Neolamprologus pulcher). General and Comparative Endocrinology, 161: 202-207.

Vissio, P. G., L. Andreone, D. A. Paz, M. C. Maggese, G. M. Somoza \& C. A. Strüssmann. 2002. Relation between the reproductive status and somatolactin cell activity in the pituitary of pejerrey, Odontesthes bonariensis (atheriniformes). Journal of Experimental Zoology, 293: 492-499.

White, S. A. \& R. D. Fernald. 1997. Changing through doing: behavioral influences on the brain. Recent Progress in Hormones Research, 52: 455-73.

Wisenden, B. D. 1995. Reproductive behaviour of free-ranging convict cichlids, Cichlasoma nigrofasciatum. Environmental Biology of Fishes, 43: 121-134.

Zhu, Y. \& P. Thomas. 1996. Elevations of somatolactin in plasma and pituitaries and increased a-MSH cell activity in red drum exposed to black background and decreased illumination. General Comparative Endocrinology, 101: 21-31.

Submitted December 9, 2010

Accepted May 16, 2011

Published September 16, 2011 